\title{
Interpretation of Economic Growth and Water Pollution Intsity Based on EKC model
}

\author{
LI Qiang ${ }^{1,2}$, HUANG Jianmin ${ }^{1, *}$, WANG Wenrui ${ }^{1}$, WANG Xuerong ${ }^{1}$ \\ ${ }^{1}$ Information Engineering College, Lanzhou University of Finance and Economics, Lanzhou, Gansu 730020, China \\ ${ }^{2}$ Key Laboratory of E-commerce,Lanzhou University of Finance and Economics, Lanzhou, Gansu 730020, China
}

\begin{abstract}
Based on the extended Environmental Kuznets model (EKC) and the spatial econometric method, this paper analyzes the emission intensity data of water pollution of Chinese provinces and cities from 2004 to 2018 to identify the key factors that could result in water pollution by different periods of time and by different regions as well as to initiate discussions over potential policies to be taken in the future. The results have two implications: on the one hand, water pollution is highly spatially correlated among different Chinese regions and the economic growth indicators such as GDP per capita and the number of lights show an inverted U-shaped nonlinear relationship with the intensity of water pollution emissions. As water pollution demonstrates both leakage effect and spillover effect, it is important to strengthen the implementation strategy featuring comprehensive planning and joint prevention and control. This paper also locates the performance of each region on the EKC curve. As demonstrated in the results, Shanghai, Beijing and Tianjin have become the first ones to manage to cross the inflection point and maintain at this level. Zhejiang, Jiangsu, Shandong and other eastern coastal areas are situated in the peak of the EKC curve, with enormous emission reduction pressure. Most of the provinces in the central region are located at the left side of the peak, and are suffering from serious water pollution resulted from rapid economic growth. Meanwhile, the intensity of water pollution in the western region of China is increasing rapidly. It is integral to seize the opportunity of supply-side reform to speed up the industrial restructuring, and try not to repeat the old lesson of treatment after pollution. In conclusion, it is suggested that governments at all levels should formulate and customize their policies based on their location on the EKC curve, so as to achieve positive dynamics between economic growth and water pollution control.
\end{abstract}

\section{Introduction}

Since the launch of reform and opening up policy, with accelerated processes of industrialization and urbanization, China's ecological environment is confronted with unprecedented pressure and especially after the 21 st century, receives irreversible negative impact inflicted by the economic growth model characterized by extensive development.. In particular, the shortage of water resources and water pollution are two of the most prominent environmental problems in China, which, if not solve properly, would be likely to hinder the high-quality development of China's economy and compromise the improvement of Chinese people's living standards and welfare in the future. Since the State Council issued and implemented the Action Plan for Water Pollution Prevention and Control in April 2015, the overall quality of water environment has been improved, though, it still has long way to go to fulfill the water prevention and control target. It is necessary to speed up solving the water pollution problems and maintain the ability to develop the economy at the same time. Therefore, exploring the relationship between water pollution and economic growth is of great practical significance for maintaining sustainable economic development for the regions.

Since Grossman and Kureger put forward the Environmental Kuznets Curve, the discussion on the relationship between economic growth and environmental pollution has become a hot topic in the field of energy economy and sustainable development both at home and abroad with an implication that : when a country's economic development is at a low level, its economic growth would deteriorate its environmental pollution, while for the countries that have reached a certain size of economy, their environment will be gradually improved entering into a sound and coordinated development stage between economy and environment ${ }^{[1]}$. The results of previous studies on the relationship between economic development and water pollution are inconsistent, which may conform to the Environmental Kuznets curve (EKC) ${ }^{[2]}$. Some researchers have pointed out that the relationship between economic development and environment could present itself in an inverted U-shape, N-shape or linear fashion and there could exist large regional heterogeneity ${ }^{[3 \cdot 4]}$.

About the authors: LI Qiang, born in 1973, master, professor, mainly engaged in e-commerce data mining and machine learning; HUANG Jianmin (1997-), born in Ganzhou Jiangxi Province, is a master candidate. His research interests include natural language processing and machine learning; E-mail: Huangjm97@163.com 
With the rapid development in spatial econometrics in recent years, more and more domestic research is conducted based on EKC model to understand the spatial correlation and spillover effect ${ }^{[5]}$ of environmental pollution. While most of the existing research methods on the relationship of economic growth and pollution mainly feature time series and panel data analysis, this paper applies EKC model to grasp the spatial correlation between economic growth and water pollution intensity, its influencing factors and the shape of EKC curve. Although the above-mentioned studies have reached different conclusions regarding the characteristic summary of EKC curve, they have unanimously and clearly pointed out that air pollution is spatially corelated and it has spillover effect ${ }^{[6,7]}$. Given existing studies and the spatial correlation characteristic of environmental problems, this paper builds a spatial econometric model regarding economic development and water pollution intensity to explore the shape and characteristics of Kuznets curve of water pollution. So far, the existing studies have proved the applicability of EKC curve in China. As only a few researchers have shown the different shapes of EKC curve and the location changes on the curve of different provinces and cities by region and period of time, this paper would determine the location of provinces and cities on the EKC curve from the perspective of time series, and extend the research period to 15 years in order to render results that are more robust and relevant and provide empirical references and policy support for cross-region improvement of water environment and development of economy.

\section{Model Construction and Variable Selection}

\subsection{Model Construction}

Based on the EKC model and the research focus of this paper, the benchmark models (1) and spatial Dubin model ${ }^{[8]}(2)$, (3) are constructed as follows:

$$
\begin{aligned}
& P O L_{i t}=\alpha+\lambda_{1} g d p_{i t}+\lambda_{2}\left(g d p_{i t}\right)^{2}+\beta_{1} T F P_{i t}+ \\
& \beta_{2} I S_{i t}+\beta_{3} E I_{i t}+\beta_{4} U R_{i t}+\mu_{i} \\
& P O L_{i t}=\alpha+\rho \sum_{j=1}^{N} W_{i j} P O L_{i t}+\beta X_{i t}+ \\
& \theta \sum_{j=1}^{N} W_{j i} X_{i j t}+\mu_{i}+v_{t}+\varepsilon_{i t} \\
& \varepsilon_{i t}=\varphi \sum_{j=1, j \neq i}^{N} W_{i j} \varepsilon_{i t}+\mu_{i t}
\end{aligned}
$$

Of the models, $P O L_{i t}$ is the explained variable, an indicator of the water pollution severity in the region; $W P O L_{i t}$ is the spatial lag factor of water pollution, representing the weighted water pollution severity in adjacent regions; $\rho$ is the spatial autoregressive coefficient, standing for the spatial impact of air pollution of the adjacent region on the local region; $i$ and t represent the region and time respectively, $\boldsymbol{\varepsilon}_{\boldsymbol{i t}}$ is the residual error, $\boldsymbol{\mu}_{\boldsymbol{i}} 、 \boldsymbol{v}_{\boldsymbol{t}}$ respectively stand for regional and temporal effects, W represents the spatial weight matrix, and $\mathrm{X}$ stands for the core explanatory variable and control variable.
Most studies on the relationship between water pollution and economic growth are based on the Kuznets model (EKC) proposed by Grossman with the economic growth as the core explanatory variable, which only considers the effect of economic growth on water pollution and fails to take into account the impact of other important economic variables. On the basis of EKC model, this paper adds determinants such as industrial structure, urbanization level, energy intensity ${ }^{[9]}$ and technological progress, and tries to investigate the influence mechanism of the aforementioned factors on water pollution via the analysis of 15 years of panel data of 30 provinces (cities) in the mainland (excluding Hong Kong, Macao, Taiwan and Tibet) from 2004 to 2018.

The explanatory variable, represented by water pollution emission intensity (POL), is the ratio of water pollution emissions to regional industrial output value. This paper uses real GDP per capita as the variable representing the level of economic growth (GDP); the ratio of electricity consumption to GDP represents energy intensity (EI); the ratio of tertiary industry scale to secondary industry scale represents industrial structure (TTI); and the proportion of urban population in the total population represents the level of urbanization (UR). The technical progress is represented by Malmquist-hs TFP index ${ }^{[10]}$. Besides, labor force, capital stock and energy consumption are selected as input factors, while expected output of real GDP and unexpected output of water pollution are selected as output factors, with labor force represented by the number of employees in each region, capital stock represented by social fixed assets investment and estimated by perpetual inventory method of $k_{j, t}=$ $(1-\delta) K_{j, t-1}+I_{j, t}$, where $\mathrm{K}$ and I stand for capital stock and newly added social fixed assets investment respectively, $\mathrm{t}$ and $\mathrm{j}$ represent year and region respectively, and $\delta$ stands for depreciation rate of fixed assets. Given the possibility that China's energy consumption data is underestimated, the annual electricity consumption of each region is used to represent the energy consumption level of that region. The raw data presented in this paper is all taken from China Statistical Yearbooks and China Environmental Yearbook. All variables mentioned above are included in the model in the form of logarithm.

\section{Equations and mathematics}

\subsection{Spatial Correlation Test}

In this paper 0-1 adjacent weight matrix (W1), economic distance matrix (W2) as well as geographical distance matrix (W3) are used as the spatial weight matrix and spatial autocorrelation index ${ }^{[11]}$ is a concept of spatial econometrics usually used to determine whether water pollution is spatially correlated among different regions. When the index approaches 1 , it indicates that there is a positive spatial correlation regarding water pollution among different regions; when the index drops down to near - 1 , a negative spatial correlation is demonstrated; when the index is close to 0 , it indicates that there is no spatial correlation in the case of water pollution among 
different regions. Figure one is the trend of global Moran's I index from 2004 to 2018 calculated based on W1 matrix where all of the data points are positive and have passed the $1 \%$ significance testing, a suggestion that there is an obvious spatial correlation among water pollution of the 30 regions, showing clusters of heavily polluted areas and clusters of lightly polluted areas. According to observation made on past 15 years of Moran's I index, the global Moran's I index regarding water pollution of different regions in China fluctuates from 0.2 to 0.4 , which indicates that the spatial effect cannot be ignored in the study of the EKC problems in different provinces.

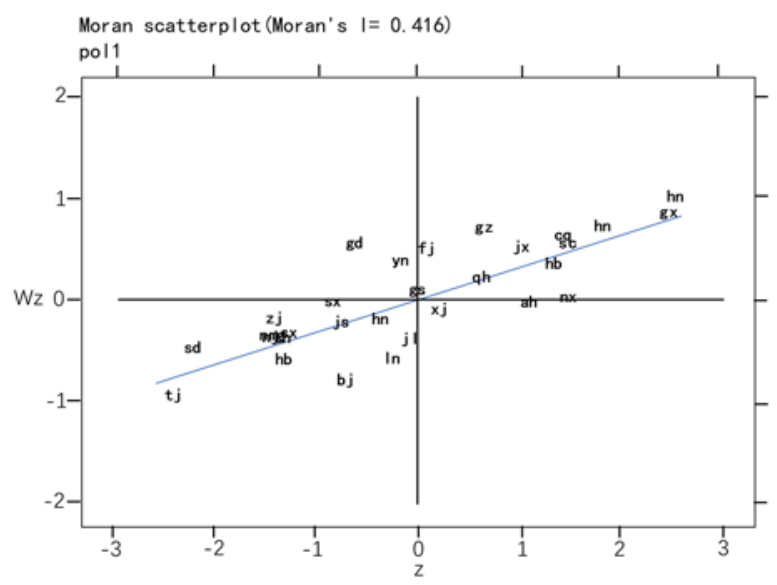

Fig. 1. Scatter Diagram of Moran's I Index of Water Pollution in Different Provinces, 2004.

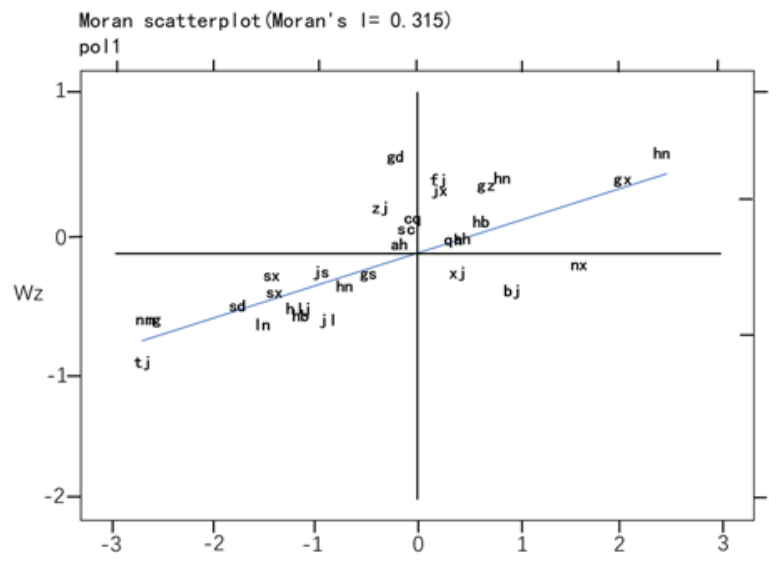

Fig. 3. Scatter Diagram of Moran's I Index of Water Pollution in Different Provinces, 2010.
While the global index could reflect the overall spatial correlation, it may fail to pay enough attention to local regional specificity. Therefore, it is necessary to introduce the local correlation index Ii (LISA) to help with the measurement. When $\mathrm{Ii}>0$, it means that there is a positive correlation between area $i$ and its surrounding areas, and areas with similar characteristics of pollution emission are clustering together in the form of $\mathrm{H}-\mathrm{H}$ or $\mathrm{L}-\mathrm{L}$ agglomeration; when Ii $<0$, it indicates a negative correlation, demonstrating either the H-L type agglomeration or the L-H type agglomeration.

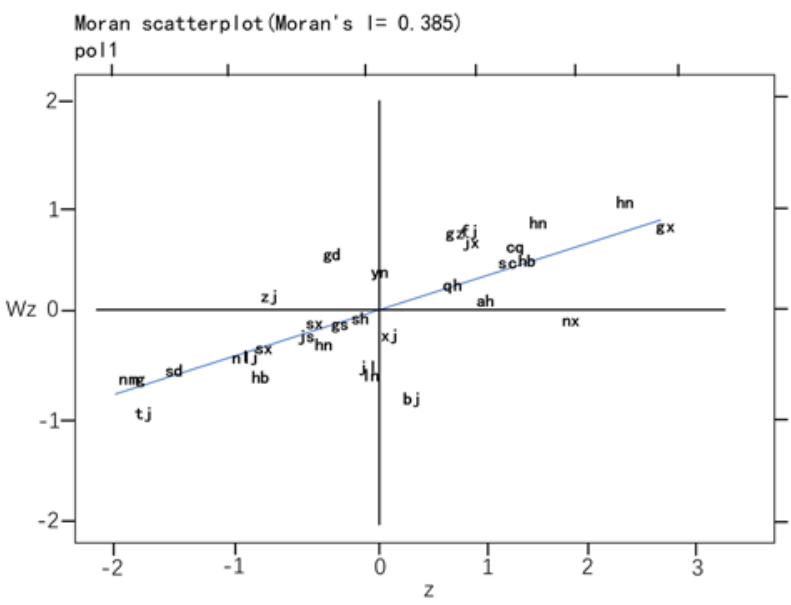

Fig. 2. Scatter Diagram of Moran's I Index of Water Pollution in Different Provinces, 2007.

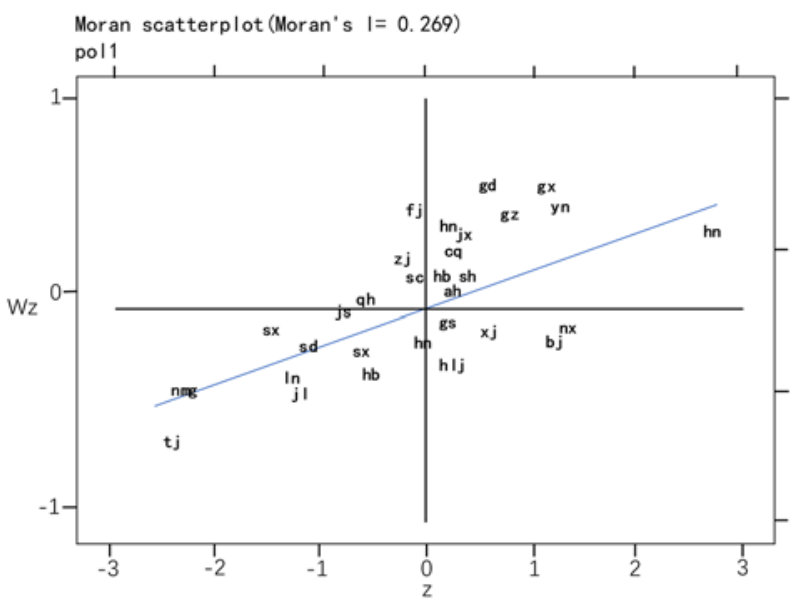

Fig. 4. Scatter Diagram of Moran's I Index of Water Pollution in Different Provinces, 2013. 


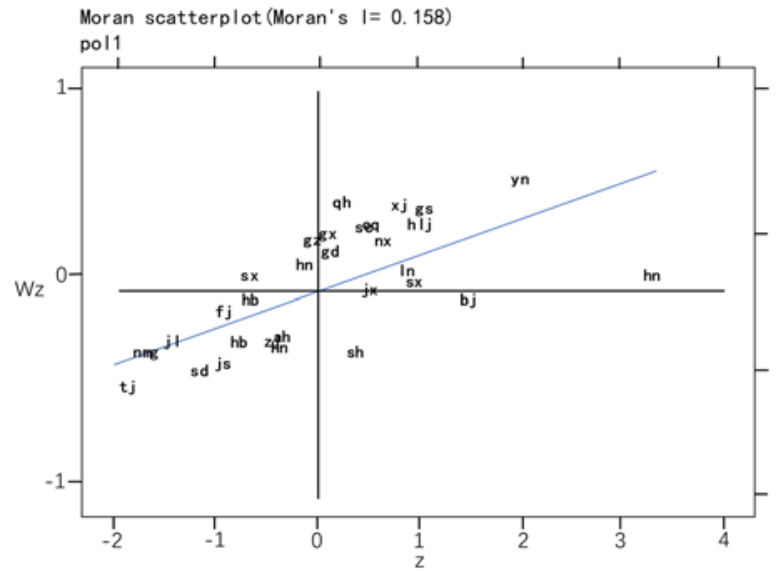

Fig. 5. Scatter Diagram of Moran's I Index of Water Pollution in Different Provinces, 2015.

It can be seen from figure 1-6 that water pollution conditions of various regions in China have significant spatial correlation, and patterns featuring double highs and double lows in the first and third quadrants are dominant. It is demonstrated in the figures that there are 8 heavily polluted areas clustering together in the first quadrant, including Henan, Guangxi, Guangzhou, Jiangxi, Chongqing, Fujian, Sichuan and Hubei. Provinces with concentration of highly polluted areas boast water resources and feature a relatively simple industrial structure with a main focus on traditional manufacturing sector. Although these provinces are undergoing the process of transformation, the effect of the extensive development approach that they have long adopted will not abate immediately. The central region, including Hubei, Henan and Jiangxi, connects the two economic growth poles of Beijing, Tianjin, Hebei and Yangtze River Delta. With the strategy for the Rise of the Central Region and the promotion of the value chain division, the central region has overtaken industries featuring relatively high energy consumption and pollution emission transferred from the eastern coastal areas, so the intensity of water pollution emissions in this region can be hard to reverse in the short term. In the third quadrant are shown 8 clustered areas featuring light pollution, including Tianjin, Shandong, Inner Mongolia, Liaoning, Jilin, Heilongjiang, Jiangsu, Shanghai and Shanxi. Most of the areas are located in the central and western and northeastern regions where the water resources are relatively limited and in the eastern coastal region that are more economically developed. The overall wastewater discharge rate in these areas is low, as the former ones have limited use of water resources during production process and the latter usually are equipped with relatively sophisticated pollution control and green production technologies.

According to the analysis above, the spatial agglomeration effect of water pollution is closely related to factors such as economic development level, energy consumption, industrial structure and others. Most of the water pollution indicators selected by this paper are derived from industrial economic activities,, suggesting that the agglomeration effect of water pollution is by nature a result of agglomeration of industrial economic activities. Therefore, to resolve the environmental

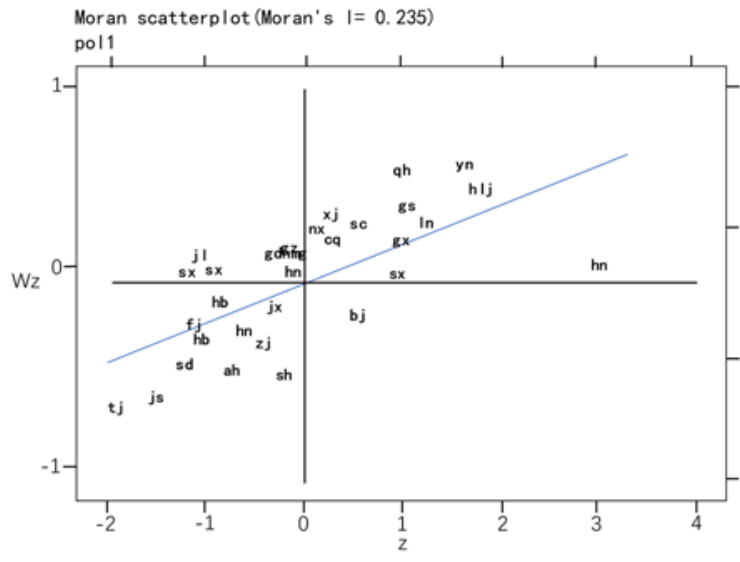

Fig. 6. Scatter Diagram of Moran's I Index of Water Pollution in Different Provinces, 2018

problem, it is important to make adjustments to the economic development model and the industrial structure in different regions.

As shown in the analysis above, there is a positive and long-term stable global correlation among water pollution in various regions of China. A rigorous analysis through the extended EKC spatial econometric model is conducted in the following pages to estimate the scale of the impact of this spatial effect on economic development and water pollution.

\subsection{Analysis of Econometric Regression Results}

This paper first uses the least squares method of nonspatial effects (OLS) to prove the rationality of using the spatial econometric method, with the results shown in the model (1) in Table 3. The model (2)- (4) are the fixed effect estimation results under spatial Dobbin model. In model (3)-(6), the number of night light can be used as a good alternative indicator of economic growth to test the robustness of the core conclusions ${ }^{[12]}$. By comparing the coefficients of variables of the non-spatial model and the spatial model, it is found that the latter is significantly better than the former, which is a proof of the legitimacy of the spatial econometric model. As to the selection of matrices, the coefficient $\rho$ of the spatial econometric model under three kinds of weight matrices has passed the significant test. On the whole, the economic matrix has delivered better regression results than geographical matrix and adjacent matrix, which has verified that water pollution could spread geographically and transfer through cross-region economic cooperation and production process. A significant positive value of $\rho$ means that with every $1 \%$ of increase of water pollution in the surrounding area, the pollution in the local area will rise by at least $0.0546 \%$. The results indicate that the intensity of water pollution emissions of each region in China not only depends on its own economic development level, industrial structure and its original resource distribution conditions, but also is affected by its surrounding areas, with certain spatial agglomeration characteristics and spillover effect. 
Table 1. Results of OLS, SLM and SEM Fixed Effect Estimation.

\begin{tabular}{|c|c|c|c|c|c|c|c|}
\hline Variable & (1) & (2) & (3) & (4) & (5) & (6) & (7) \\
\hline \multirow[t]{2}{*}{ GDP } & $-0.882 * * *$ & $-1.055^{* * *}$ & $-1.112^{* * *}$ & $-1.096^{* * *}$ & & & \\
\hline & $(0.0460)$ & $(0.111)$ & $(0.0901)$ & $(0.0949)$ & & & \\
\hline \multirow[t]{2}{*}{ UR } & $0.684 * * *$ & $0.559^{* * *}$ & $0.707 * * *$ & $0.732 * * *$ & $0.506^{* * *}$ & $-0.316^{* *}$ & $-0.258^{*}$ \\
\hline & $(0.177)$ & $(0.216)$ & $(0.182)$ & $(0.187)$ & $(0.174)$ & $(0.155)$ & $(0.155)$ \\
\hline \multirow[t]{2}{*}{ TTI } & $0.533 * * *$ & $0.487 * * *$ & $0.425 * * *$ & $0.500 * * *$ & $0.725 * * *$ & $0.830 * * *$ & $0.858^{* * *}$ \\
\hline & $(0.0426)$ & $(0.0643)$ & $(0.0504)$ & $(0.0535)$ & $(0.0593)$ & $(0.0507)$ & $(0.0538)$ \\
\hline \multirow[t]{2}{*}{ EI } & 0.0932 & $0.250^{* * *}$ & $0.139 * * *$ & $0.0983^{*}$ & $0.317^{* * *}$ & $0.341^{* * *}$ & $0.239^{* * *}$ \\
\hline & $(0.0590)$ & $(0.0621)$ & $(0.0532)$ & $(0.0542)$ & $(0.0667)$ & $(0.0656)$ & $(0.0665)$ \\
\hline \multirow[t]{2}{*}{ TFP } & 0.102 & $0.196^{* *}$ & $0.174 * * *$ & $0.0890^{*}$ & $0.288^{* * *}$ & $0.126^{*}$ & $0.148^{* *}$ \\
\hline & $(0.0675)$ & $(0.0775)$ & $(0.0631)$ & $(0.0652)$ & $(0.0812)$ & $(0.0757)$ & $(0.0756)$ \\
\hline \multirow[t]{2}{*}{ GDP2 } & $-0.000910^{*}$ & $-0.00212 * * *$ & $-0.00105^{*}$ & -0.000676 & & & \\
\hline & $(0.000547)$ & $(0.000625)$ & $(0.000537)$ & $(0.000554)$ & & & \\
\hline \multirow[t]{2}{*}{ SL } & & & & & $-1.025^{* * *}$ & $-0.838^{* * *}$ & -0.278 \\
\hline & & & & & $(0.238)$ & $(0.224)$ & $(0.208)$ \\
\hline \multirow[t]{2}{*}{ SL2 } & & & & & $-0.0868 * * *$ & $-0.0817 * * *$ & -0.00189 \\
\hline & & & & & $(0.0287)$ & $(0.0285)$ & $(0.0247)$ \\
\hline \multirow[t]{2}{*}{$\mathrm{W} * \mathrm{GDP}$} & & 0.151 & 0.214 & $0.431 * * *$ & & & \\
\hline & & $(0.204)$ & $(0.133)$ & $(0.166)$ & & & \\
\hline \multirow[t]{2}{*}{$\mathrm{W} * \mathrm{DG} 1$} & & & & & $1.415 * * *$ & $1.431 * * *$ & $1.233^{* * *}$ \\
\hline & & & & & $(0.475)$ & $(0.387)$ & $(0.384)$ \\
\hline \multirow[t]{2}{*}{$\rho$} & & $0.0546^{*}$ & $0.176^{* * *}$ & $0.0869^{*}$ & $0.418^{* * *}$ & $0.426^{* * *}$ & $0.177^{* * *}$ \\
\hline & & $(0.138)$ & $(0.0633)$ & $(0.0766)$ & $(0.0718)$ & $(0.0530)$ & $(0.0616)$ \\
\hline $\mathrm{N}$ & 450 & 450 & 450 & 450 & 450 & 450 & 450 \\
\hline $\mathrm{R} 2$ & 0.886 & 0.607 & 0.652 & 0.698 & 0.480 & 0.386 & 0.344 \\
\hline
\end{tabular}

Note: $* * *, * *$, and $*$ are significant at level of $1 \%, 5 \%$ and $10 \%$ respectively.

Specifically, the coefficient representing the influence of economic growth (GDP per capita) on the intensity of water pollution emissions remains at a level between 1.005 and - 1.112, which indicates that economic growth does not lead to serious deterioration of water pollution and on the contrary, water pollution will be reduced by at least $1.005 \%$ with every $1 \%$ of increase in GDP. Meanwhile, the coefficients of the quadratic term of GDP are all negative, a suggestion that there is an inverted Ushaped relationship between water pollution and economic growth in China. This verifies the applicability and effectiveness of EKC curve in the cases of Chinese economic samples, indicating that the intensity of water pollution emissions will increase first and then decrease with the rise of economic growth level. A positive $\mathrm{W}^{*}$ GDP coefficient indicates that there is a negative externality of economic growth among neighboring areas and the economic development in the local areas will result in a leakage effect ${ }^{[13]}$ on the surrounding environment. Therefore, regional joint prevention and control strategy must be adopted to solve environmental pollution and save the ineffective and inefficient unilateral pollution control efforts.

In terms of control variables, the impact of urbanization on the intensity of water pollution emission is significantly positive, indicating that with an accelerated urbanization process where more people move into the cities, the demand for water resources 
would significantly increase, be it in the case of household water consumption or water consumed in the industrial production processes, and would later result in higher water pollution emissions.

The regression coefficient of energy intensity is significantly positive, which indicates that the intensity of water pollution emissions would increase by at least $0.0983 \%$ with every $1 \%$ of increase in energy intensity. Fossil fuels such as coal still dominate China's energy consumption, and their emission coefficient and their impact on the environment are significant. Therefore, the energy consumption structure must be transformed to eventually achieve green development.

The influence coefficients of technological progress under the three weight matrices are positive, especially significant at the confidence level of at least $10 \%$, which suggests that it does not help improve the water pollution conditions. As for the reasons, technological progress is usually divided into two types, including progress in production technology and that in green emission reduction technology. The former one is conducive to the improvement of productivity, while the latter affects the intensity of pollution emissions. At present, China pays more attention to the improvement of production technology than to the development of green technology As a result, the expansion of production scale may lead to an increase of water pollution. Therefore, it is necessary to continuously guide enterprises to research and develop green technology and encourage them to adopt green transformation.

The regression coefficient of industrial structure ranges between $0.425-0.450$,suggesting that the higher the proportion of secondary industry, the greater the intensity of water pollution. Therefore, to achieve the strategic goal of green economic growth, it is integral to speed up the pace of industrial structuring and upgrading, and vigorously develop high-tech industry and modern tertiary industry.

In the robustness tests of model (5)- (7), the core conclusion is consistent with the previous studies, which further proves the model setting and conclusions reasonable and scientific.

\section{The Re-interpretation of EKC Curve}

The results of spatial econometric model show that both the first and square terms of GDP have passed the significance test of $10 \%$, and their regression coefficients are positive and negative respectively, which basically conforms to the characteristics of an "inverted U-shaped" EKC curve. When the economic development is at a low level, environmental quality in some cases would be compromised in exchange for high economic performances. Therefore, in some cases, with the improvement of economic development level, the environment is deteriorating. However, when the development level increases to a certain critical point, the government and the public crowd will place higher requirements for environmental quality, or in other words, the deterioration of environmental quality would hinder the further development of economy. At this time, the requirements of some economic development goals are lowered down, and with funds and energy put into environmental governance, later the environmental quality will be improved along with the increase of economic development level.

According to statistical data, since the implementation of the 13th five-year plan, China's wastewater discharge volume increased from 65,919.22 million tons in 2011 to the peak of 73,532.27 million tons in 2015and then followed a descending trend all the way to $69,906.54$ million tons in 2018. However, this does not mean that the water pollution has reached an inflection point $=$. While China is still experiencing a thorough economic transformation[14], both the positive and negative factors affecting emissions of pollutants could coexist, which may lead to a delayed arrival of the inflection point for the air pollution, or demonstrate a continuous oscillation characteristic of the curve at a high level, indicating that there is still a long way to go to fulfill the comprehensive improvement of environmental quality.

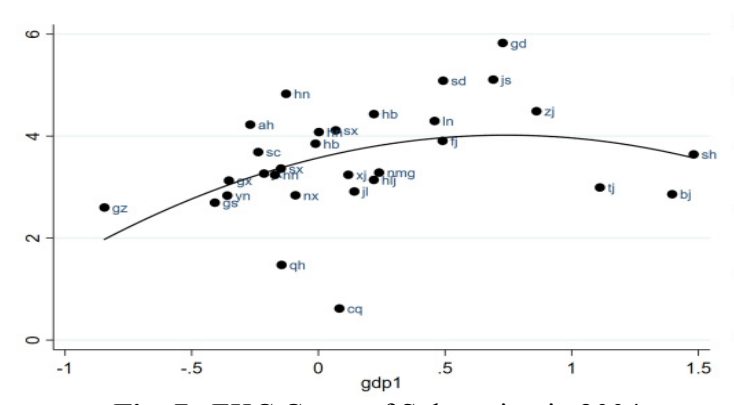

Fig. 7. EKC Curve of Sub-region in 2004

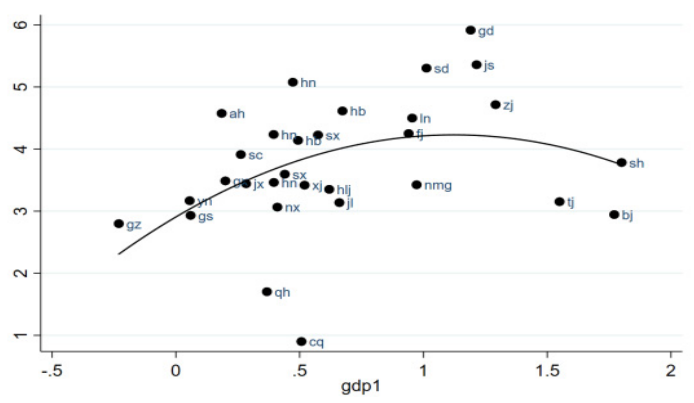

Fig. 8. EKC Curve of Sub- region in 2007 


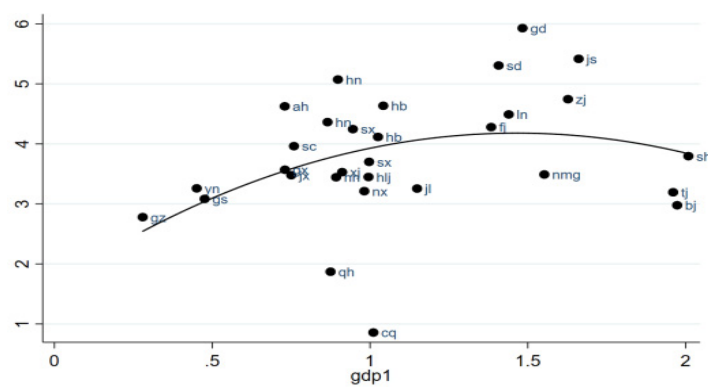

Fig. 9. EKC Curve of Sub- region in 2010

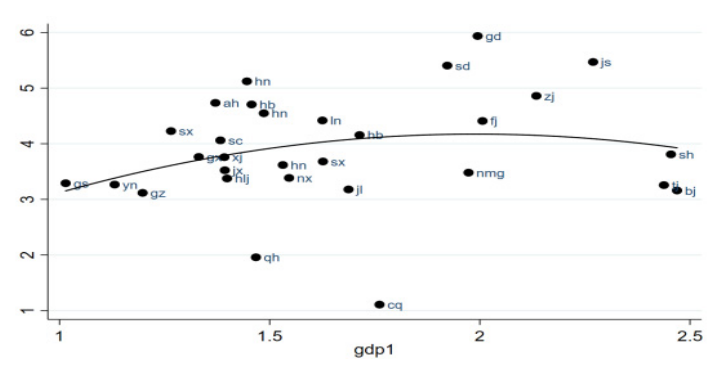

Fig. 11. EKC Curve of Sub- region in 2016

Taking into account the heterogeneity of economic development level of and development model adopted by different regions, based on the basic model and principles of EKC, this paper uses the data of water pollution and economic growth from 2004 to 2018 to map a curve with the horizontal axis representing the level of economic growth (GDP)and the vertical axis representing the intensity of water pollution emission (in the form of Pol)The approximate shape of the curve is consistent with the conclusion derived from the spatial econometric estimation that the relationship between economic growth and water pollution is an inverted U-shaped curve. In Figure 7-12 are shown the locations of each region on the EKC curve in 2004, 2007, 2010, 2013, 2016 and 2018, which can provide some ideas for future water pollution control.

According to the figures, it can be seen that: 1 . Generally speaking, China's economically developed and underdeveloped regions have relatively good environment, while regions with the middle-level income suffer from poor environmental quality. 2. As time passes, changes in the morphological characteristics of the "inverted U-shaped curve" become less and the EKC model has been verified in practice. 3. The inflection points for water pollution improvement for different regions come at different periods of time and as time goes on, the number of provinces and cities crossing and approaching their inflection point is gradually on the rise. The areas that have completely passed the inflection point include Shanghai, Tianjin and Beijing, all of which are economically developed areas located in the coastal region. The reasons behind are as follows: on the one hand, as the center of Beijing-Tianjin-Hebei region and Yangtze River Delta, the above-mentioned three municipalities have relatively large economic development scale and total economic volume. Meanwhile, thanks to the implementation of the economic transformation and strategic transfer plan ${ }^{[15]}$, they all have a light industrial structure and low intensity of pollution emissions; on the other, the municipal governments attach great importance to improving environmental quality. The areas that have

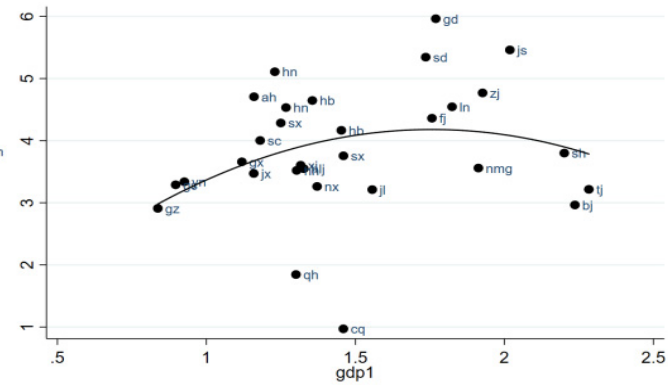

Fig. 10. EKC Curve of Sub- region in 2013

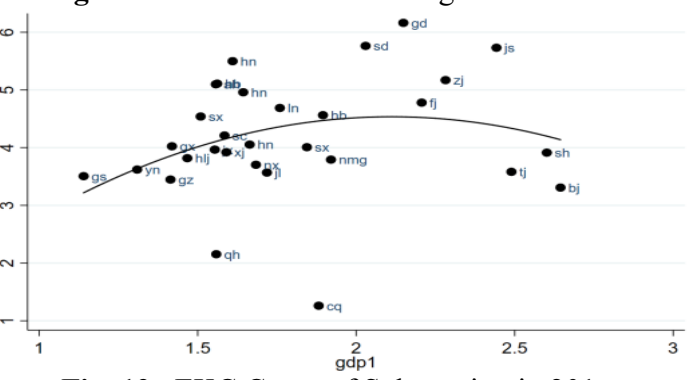

Fig. 12. EKC Curve of Sub- region in 201

just passed their inflection point but still suffer from a high level of pollution include Zhejiang, Jiangsu, Guangdong, Shandong and Liaoning. It is shown in the figures that the proportion of industries featuring high energy consumption in these areas is still high and there is still a long way to go to improve the environmental quality of these areas. Most provinces in the central region such as Hubei, Henan, Hunan, Shanxi and Henan are located at the peak of the left half of the EKC curve and their wastewater discharge volume are predicted to reach the peak soon. As the central region has a high proportion of medium and low-end industries and is now undertaking industrial transfer from the eastern coastal areas, it might remain at the peak level for a pretty long period of time. Based on the International experience, economies are likely to stay at the peak level for approximately 10 years. The western underdeveloped region is still in the climbing stage on the EKC curve with a lagging economic growth and intensifying deterioration of environmental quality. The pollution resulted from wastewater discharge in the process of industrialization in this region is still a problem that should be focused on. When the economic growth will no longer lead to worsening environmental pollution for this region remains unclear and it shows yet again the difficulty and urgency of practicing pollution control.

Of course, the discussion based on the EKC model is a summative description and verification derived from empirical data, which shall not be used to predict the future development trends of current situation. Governments at all levels must clearly realize that economic development will not automatically solve the current water pollution problem, and only with universal importance attached and continuous exploration made can this situation be reversed.

\section{Conclusion}

This paper analyzes statistics regarding the intensity of water pollution emissions in 30 regions of China from 2004 to 2018 and conducts a spatial autocorrelation test ${ }^{[16]}$ 
on the pollution situations of these 30 regions during these 15 years by using the spatial autocorrelation Moran's I index. The extended Environmental Kuznets model (EKC) and spatial Dubin model are used for the spatial regression analysis of water pollution and its influencing factors in China. The paper arrives at the following conclusions:

1. There is a spatial autocorrelation and regional local correlation regarding the intensity of water pollution emissions in various Chinese regions in the recent 15 years;

2. The regression results of spatial Dubin econometric model show that economic development and intensity of water pollution emissions are negatively correlated, with negative externalities such as leakage effect and pollution spillover effect. Since the quadratic term is negative, it indicates that the hypothesis of an "inverted U-shaped" non-linear EKC curve is supported by empirical data.

3. According to EKC curve, it is found that the higher the economic development level, the faster the speed to cross the peak and inflection point. Shanghai, Tianjin and Beijing are in the first tier, followed by eastern coastal areas such as Zhejiang, Guangdong, Shandong and others. Most of the central region is close to the peak on the left half of the curve, while the western region is still in the climbing stage. To sum up, it is necessary to build a regional joint prevention and control mechanism, form joint effort in pollution control, promote overall social changes through sustainable means such as optimization of the economic structure, transformation of the energy structure, as well as innovation and breakthrough of green technologies, and build a green development road with benign dynamics between economic development and environmental improvement.

\section{References}

1. Grossman,G.M. and Krueger, A.B. Environmental impacts of a North American Free Trade Agreement. NBER Working Paper, No. 39 14, (1991)

2. Grossman,G.M. Galeotti M, Lanza A. Desperately seeking environmental Kuznets. Environmental Modelling \& Software, Vol.20, No. 11: 1379-1388, (2009)

3. WU Zhaodan, Ye Quanliang,Water pollution loads and shifting within China's inter-province trade. Journal of Cleaner Production, Vol 259, 120879 , (2020)

4. Xie Qichang, Xu,Xin, Liu Xiaqing,Is there an EKC between economic growth and smog pollution in China? New evidence from semiparametric spatial autoregressive models, Journal of Cleaner Production, Vol. 220: 873-883, (2019)

5. Fang-Yan X U, Chen K M . Spatial Correlation and Spatial Spillover Effect on Economic Growth of the Urban Agglomeration in the Guangdong-Hong Kong-Macao Greater Bay Area. Economic Forum, (2019)
6. Liu Huajun ,Pei Yanfeng An Empirical Test of the Environmental Kuznets Curve of China's Haze Pollution,Statistical Research, Vol.34,No.3:45-55, (2017)

7. Fu Yunpeng, MaShucai,SongQi,Spatial Econometric Analysis of Regional Carbon Intensity,Statistical Research, Vol.32,No. 6:58-65, ( 2015)

8. Chao Z, Guo H, Shen T . Evolution Characteristics of China Space Market Integration Based on The Law of One Price and Spatial Dubin Model[J]. Finance \& Economics, (2016)

9. Do urbanization and industrialization affect energy intensity in developing countries?[J]. Energy Economics, 2,37(may):52-59,(2013)

10. Gao Y Q, Yi-Qi H E . Study on Grain Direct Subsidy Efficiency in Main Grain Producing Areas Based on Malmquist TFP Index. Journal of South China Agricultural University(Social Science Edition), (2010)

11. Oden N . Adjusting Moran's I for population density[J]. Statistics in Medicine, 14(1),(1995)

12. Henderson, J.V., A Storeygard, and D.N.Weil, A Bright Idea for Measuring Economic Growth, American Economic Review, Vol.101,No.3,194199,(2011)

13. Letokhov V S, Makarov A A . "Leakage" effect as an exciting mechanism of high vibrational levels of polyatomic molecules by a strong quasi-resonant laser ir field[J]. Optics Communications, 17(3):250253,(1976)

14. Org Z . China's Great Economic Transformation[J]. Cambridge Books, Volume 64,(2008)

15. Zegeer C, Nabors D, Gelinne D, et al. Pedestrian Safety Strategic Plan: Recommendations for Research and Product Development[J]. Pedestrian Safety, (2010)

16. Sokal R R, Wartenberg D E . A Test Of Spatial Autocorrelation Analysis Using An Isolation-ByDistance Model[J]. Genetics, 105(1):219-237,(1983) 